\title{
Antenatal Care: Utilization Rate and Barriers in Bosaso-Somalia, 2019
}

\author{
Elmi Omar Haji EImi ${ }^{1, ~ *, ~ N u r ~ A h m e d ~ H u s s e i n ~}{ }^{2}$, Abdiwahab Mohamed Hassan $^{3}$, \\ Abdiwahid Mohamed Ismail ${ }^{4}$, Abdullah Abdulrizak Abdulrahman ${ }^{5}$, Abdulkadir Mohamed Muse ${ }^{6}$ \\ ${ }^{1}$ Faculty of Medicine and Health Sciences, East Africa University, Bosaso, Somalia \\ ${ }^{2}$ Department of Public Health, University of Health Sciences - Bosaso and Red Sea University, Bosaso, Somalia \\ ${ }^{3}$ Somali Institute for Development Research and Analysis (SIDRA), Minnesota, USA \\ ${ }^{4}$ Department of Pharmacy; University of Health Science-Bosaso, Bosaso, Somalia \\ ${ }^{5}$ Alberta Public Health Association, Alberta, Canada \\ ${ }^{6}$ Somali Institute for Development Research and Analysis (SIDRA), Garowe, Somalia
}

Email address:

elmiomar11@gmail.com (E. O. H. Elmi),nurdeeq@gmail.com (N. A. Hussein), abdiwahab49@gmail.com (A. M. Hassan), abdiwahidedu@gmail.com (A. M. Ismail),jiindhe4@gmail.com (A. A. Abdulrahman), abdukadirmusse09@gmail.com (A. M. Muse)

${ }^{*}$ Corresponding author

\section{To cite this article:}

Elmi Omar Haji Elmi, Nur Ahmed Hussein, Abdiwahab Mohamed Hassan, Abdiwahid Mohamed Ismail, Abdullah Abdulrizak Abdulrahman, Abdulkadir Mohamed Muse. Antenatal Care: Utilization Rate and Barriers in Bosaso-Somalia, 2019. European Journal of Preventive Medicine. Vol. 9, No. 1, 2021, pp. 25-31. doi: 10.11648/j.ejpm.20210901.15

Received: February 5, 2021; Accepted: February 14, 2021; Published: February 27, 2021

\begin{abstract}
Mothers and children are among the most vulnerable population groups requiring special attention and care. The fourth and fifth Millennium Development Goals (MDGs) address child mortality and maternal health, respectively. Although maternal mortality rate (MMR) has declined globally between 1990 and 2015 by 44\%, the World Health Organization (WHO) estimates that $99 \%$ of global maternal mortality takes place in the developing countries. Somalia has one of the highest maternal and child mortality rates in the world, with 732 mothers dying in every 100,000 live births. Mainly, such high MMR is the outcome of the devastating civil wars that disrupted the country's health infrastructure with limited antenatal care (ANC) coverage ( $26 \%$ only). We conducted a community-based cross-sectional study using a quantitative approach to identify ANC utilization rate and barriers among mothers having a child less than one year of age in Bosaso from October - November 2019. A sample size of 384 mothers was interviewed by using a structured questionnaire, and SPSS was used to analyze the collected data. This study found that (84.1\%) of the respondents utilized ANC services during their last pregnancy, but only $28 \%$ of them completed the recommended number of ANC visits for pregnant women. The main barriers hindering the utilization of ANC services were identified to be distance of the health centers, financial constraints, inadequate knowledge and attitude of the respondents and their husbands, poor attitude of the healthcare providers, and time and family-related issues. Based on the findings of the study, we recommend uplifting the awareness of the family/mothers for the utilization of antenatal care services in health facilities.
\end{abstract}

Keywords: Antenatal Care Utilization, Mothers, Antenatal Care Barriers, Bosaso

\section{Introduction}

There is no doubt that health is a human right [1]. Mothers and children are among the most vulnerable population groups requiring special attention and care. The fourth and fifth Millennium Development Goals (MDGs) address child mortality and maternal health, respectively [2]. Although the maternal mortality rate (MMR) has declined globally between 1990 and 2015 by 44\% [3], the World Health Organization (WHO) estimates that $99 \%$ of global maternal mortality takes place in the developing countries [4].

Because of the civil war and political setbacks, Somalia is one of the least developed countries in the world [5]. This political turmoil has had negative impacts on its development, 
particularly the health sector [6]. This sector remains weak, poorly resourced and inequitably distributed since 3.2 million women and men in Somalia are in need of emergency health services. Despite the international and national efforts in restoring Somalia's health system, the country has one of the highest maternal and child mortality rates in the world $[7,8]$, with 732 mothers dying in every 100,000 live births [7]. Such high MMR is, mainly, the outcome of the devastating civil wars that disrupted the country's health infrastructure [9-12], resulting in limited antenatal care (ANC) with $26 \%$ coverage only [8].

Because the available reproductive health services in Somalia are limited [8, 14], mothers' utilization of those services is a significant concern $[15,16]$. Underutilization of already scarce reproductive health services will only make the maternal health status in Somalia worse. Therefore, to improve maternal and child health, reproductive health services, such as ANC [13], should be in place.

In general, the utilization of maternal health services is affected by several factors, including its availability, accessibility, affordability, timely care delivery, mothers' health literacy, and the attitude of healthcare providers [1722]. Although universal access to ANC services is essential, however, if utilization barriers are not identified and removed, progress towards reducing maternal morbidity and mortality will be hindered.

Unfortunately, there is minimal literature on the specific factors associated with mothers' utilization of ANC and its consequences in Somalia. Only one study, conducted in Hargeisa - Somalia [16], has reported that mothers' literacy, health workers' attitude, waiting time, male decision-making influence, and other factors impacted mothers' ANC utilization.

Since health research capacity in Somalia is limited [23], studies on reproductive health services utilization are scarce. This study will, therefore, hopefully, contribute to filling this gap. The study aims to identify the ANC services utilization rate and barriers among mothers in Bosaso, Somalia. Such information is crucial in planning for more effective maternal health services to yield a better utilization rate and eventually reduce MMR.

\section{Methods and Materials}

\subsection{Study Design and Study Area}

A community-based cross-sectional study was conducted with a quantitative approach to identify ANC utilization rate and barriers among mothers having a child less than one year of age in Bosaso from October - November 2019. Bosaso, which is located in the northeast of Somalia, is the headquarter of the Bari Region. Also, it is the principal commercial city of Puntland State of Somalia.

\subsection{Sample Size and Sampling Method}

A single population proportion formula for sample size determination was used. The antenatal care (ANC) coverage was unknown; therefore, it was taken as a $50 \%$.

The sample size became 385 , and it was determined by using the formula below:

$$
\mathrm{N}=\mathrm{Z} 2 \text { (P) (1-P) / D2 }
$$

Where

$\mathrm{N}=$ desired Sample size $\mathrm{Z}=1.96$, the factor from normal distribution

$\mathrm{P}=$ estimated period of prevalence $\mathrm{D}=$ absolute sampling error.

A multi-stage sampling technique comprising of a simple random sampling method and convenience sampling technique was used. Simple random sampling was used to select the villages, and the convenience sampling technique was used to identify households with mothers having a child less than one year. The names of all the 16 villages of Bosaso were written on pieces of paper, folded, put in a container, and shaken thoroughly. Eight of them were picked to get the villages for the study. The study participants were selected equally from the eight villages. In each village, 48 respondents were selected using a convenience sampling technique. In any house entered, Mother in the household who had a child less than one year was interviewed. This process was continued until the entire 384 sample size was selected.

\subsection{Data Collection and Analysis Methods}

Data was collected through face to face interviews of the mothers with children aged less than one year in the selected households. A structured questionnaire was used as a data collection tool.

After the fieldwork, the data was analyzed by using the SPSS program of data analyzing, version 21.

\section{Results}

\subsection{Socio-Demographic Characteristics of the Respondents}

Table 1 summarizes the socio-demographic characteristics of the respondents. For instance, the mean age of the respondents was 29 years old and about $50 \%$ of the mothers were the age group between 27-37 years. concerning the marital status of respondents, most of the mothers $87.8 \%$ were married, whereas $11.2 \%$ were divorced and the rest were widowed. Regarding education level of mothers, the majority $40.9 \%$ ) had primary level of education, whereas $35.7 \%$ were illiterate, and $13.5 \%$ of the mothers had secondary level of education, while the rest $(9.9 \%)$ were college and university level of education. regarding to husbands' educational status of the respondents, $24.5 \%$ had college and university level of education, $21.6 \%$ had primary level of education, $21.1 \%$ had secondary level of education, and the rest $20.6 \%$ were illiterate. Concerning the occupation of the respondents, most of the mothers 74\%) were housewives, $4.9 \%$ were employees, whereas $13 \%$ were self-employed, and the rest $8.1 \%$ were unemployed. A significant number of mothers $67.2 \%$ stated that their family monthly income was below 250 dollars per 
month, $25.3 \%$ had an icome from 250 to 500 dollars per moth and the rest $7.6 \%$ had an income of above 500 dollars. Finally, $43.8 \%$ of the respondents reported that their family consists of more than 6 members; $37.8 \%$ had $2-4$ members, and the rest $18.5 \%$ had $4-6$ members.

\subsection{Knowledge Level of Respondents on ANC Beneficiaries and Recommended Number of Visits}

In investigating the know-how of the respondents on ANC beneficiaries and recommended number of visits (Table 2), it was found that that the majority of the respondents $31.8 \%$ didn't know the minimum required $\mathrm{ANC}$ visits, whereas $27.3 \%, 21.9 \%$, and $11.7 \%$ of the mothers responded, respectively that three, four and two times are needed for minimum ANC visits. Only 7.3\% of them believed that one visit is enough for ANC during pregnancy. Most of the mothers $78.9 \%$ knew that both mother and fetus are ANC beneficiaries, while $12.5 \%$ of them thought that only the mother is considered as an ANC beneficiary and 3.1\% responded that ANC services are only for the fetus. The rest (5.5\%) stated that they didn't know ANC beneficiaries (Table 2).

\subsection{Utilization of ANC Services Among Mothers}

Table 3 shows that $84.1 \%$ of the mothers visited health facilities for ANC during their last pregnancy, while the rest (15.9\%) of the mothers didn't visit health facilities for ANC. As presented in Table 3, of the total respondents $84.1 \%$ attended ANC because of various reasons. Of the given reasons, about $(58.5 \%)$ of the respondents reported that they seek ANC for regular health checkups, while (41.5\%) had a specific health problem. Regarding Number of ANC visits in last pregnancy, majority of the respondents, $(59.8 \%)$, visited 2-3 times at health facilities for ANC, (27.9\%) of them attended health facilities for ANC four times or more than, while the rest (12.4\%) mothers indicated that they visit ANC centers only one time during the period of their last pregnancy. When asked about the ANC utilization in their previous pregnancy, most of the mothers $48.6 \%$ attended their first ANC during the second trimester, while 26.6\% attended their first ANC during the third trimester of gestation. The rest $24.8 \%$ attended their first ANC during the first trimester of gestation. As to the nature of ANC used, most of the mothers $91 \%$ received ANC from primary health care centers and $9 \%$ got ANC services at hospitals. Further, of the women who attended ANC, only $3.5 \%$ decided by their own to attend ANC, while $15.2 \%$ were advised by their husbands and $13.3 \%$ were motivated by their family members. The rest $8 \%$ were encouraged by friends.

\subsection{Accessibility of ANC Services}

In relation to the accessibility of the ANC services and time taken to reach the health facilities (Table 4), the respondents answered as follows: About $43.7 \%$ of the respondents took less than 30 minutes to reach health facilities, where as $43.3 \%$ of them travelled in 30 to 60 minutes. The rest $13 \%$ travelled more than one hour to reach the nearby health facility. It is worthwhile to note that most of the mothers $69.3 \%$ travelled on foot to get the service, $17.6 \%$ used public transportation and $13 \%$ travelled using private transportation including taxes or personal cars. Regarding the waiting time of the respondents for ANC services, about $45.5 \%$ of the mothers took less than 30 minutes to wait ANC service, $43.7 \%$ for 30 to 60 minutes and $10.8 \%$ waited for more than one hour to receive ANC service. The time that the respondents spent with the health care provider varied from 5 to more 25 minutes (Table 4 ).

Table 1. Socio-Demographic Characteristics of the Respondents.

\begin{tabular}{|c|c|c|c|}
\hline Variables & Categories & Frequency & Percent \\
\hline \multirow{3}{*}{ Age of Mothers } & $16-26$ & 152 & 39.6 \\
\hline & $27-37$ & 192 & 50.0 \\
\hline & $38-49$ & 40 & 10.4 \\
\hline \multirow{3}{*}{ Marital status of Mothers } & Married & 337 & 87.8 \\
\hline & Divorced & 43 & 11.2 \\
\hline & Widowed & 4 & 1.0 \\
\hline \multirow{4}{*}{ Education Level of Mother } & College/University & 38 & 9.9 \\
\hline & Secondary & 52 & 13.5 \\
\hline & Primary & 157 & 40.9 \\
\hline & Illiterate & 137 & 35.7 \\
\hline \multirow{4}{*}{ Education Level of Husband n=337 } & College/University & 94 & 24.5 \\
\hline & Secondary & 81 & 21.1 \\
\hline & Primary & 83 & 21.6 \\
\hline & Illiterate & 79 & 20.6 \\
\hline \multirow{4}{*}{ Occupation of Mothers } & Employee & 19 & 4.9 \\
\hline & Self Employed & 50 & 13.0 \\
\hline & Jobless & 31 & 8.1 \\
\hline & Housewife & 284 & 74.0 \\
\hline \multirow{3}{*}{ Monthly Family Income } & $<\$ 250$ & 258 & 67.2 \\
\hline & $\$ 250-\$ 500$ & 97 & 25.3 \\
\hline & $>\$ 500$ & 29 & 7.6 \\
\hline \multirow{3}{*}{ Family Size } & $2-4$ & 145 & 37.8 \\
\hline & $4-6$ & 71 & 18.5 \\
\hline & $>6$ & 168 & 43.8 \\
\hline
\end{tabular}


Table 2. Knowledge level of Respondents on ANC beneficiaries and recommended number of visits.

\begin{tabular}{llll}
\hline Variables & Categories & Frequency & Percent \\
\hline Regular Number of ANC visits & 1 time & 28 & 7.3 \\
& 2 times & 45 & 11.7 \\
& 3 times & 105 & 27.3 \\
& 4 times & 84 & 21.9 \\
Beneficiaries of ANC services & I don't know & 122 & 31.8 \\
& Mothers & 48 & 12.5 \\
& Embryo & 12 & 3.1 \\
& Both Mothers and Embryo & 303 & 78.9 \\
\hline
\end{tabular}

Table 3. Utilization of ANC services.

\begin{tabular}{llll}
\hline Variables & Categories & Frequency & Percent \\
\hline \multirow{3}{*}{ ANC attendance } & Yes & 323 & 84.1 \\
& No & 61 & 15.9 \\
& Total & 384 & 134 \\
Reasons for ANC usage; & Health Problem & 189 & 34.9 \\
& Regular health Checkups & 40 & 49.2 \\
Number of ANC visits in last Pregnancy; & 1 time during the pregnancy period & 193 & 10.4 \\
& $2-3$ times & 90 & 50.3 \\
First ANC visit in last Pregnancy & more than or equal to 4 & 80 & 23.4 \\
& $1-3$ months (first trimester) & 157 & 20.8 \\
Places of ANC services & $4-6$ months (second trimester) & 86 & 40.9 \\
& $7-9$ months (third trimester) & 29 & 22.4 \\
Motivating Person to visit ANC services & Hospital & 294 & 9.0 \\
& Primary Health Care centers & 49 & 91.0 \\
& Husband & 43 & 15.2 \\
\end{tabular}

Table 4. Accessibility of ANC services.

\begin{tabular}{|c|c|c|c|}
\hline Variables & Categories & Frequency & Percent \\
\hline \multirow[t]{4}{*}{ Time taken to reach Health Facility } & less than 30 minutes & 141 & 43.7 \\
\hline & 30 minutes-1hour & 140 & 43.3 \\
\hline & More than 1 hour & 42 & 13.0 \\
\hline & Total & 323 & 100.0 \\
\hline \multirow[t]{4}{*}{ Transportation means to ANC services } & Walking & 224 & 69.3 \\
\hline & Public transportation & 57 & 17.6 \\
\hline & Private & 42 & 13.0 \\
\hline & Total & 323 & 100.0 \\
\hline \multirow[t]{4}{*}{ Waiting time for ANC services } & Less than 30 minutes & 147 & 45.5 \\
\hline & 30 minutes to 1 hour & 141 & 43.7 \\
\hline & More than 1 hour & 35 & 10.8 \\
\hline & Total & 323 & 100.0 \\
\hline \multirow[t]{3}{*}{ Time taken with health care providers } & 5 minutes to 15 minutes & 116 & 35.9 \\
\hline & 15 minutes -25 minutes & 146 & 45.2 \\
\hline & more than 25 minutes & 61 & 18.9 \\
\hline
\end{tabular}

\subsection{Barriers of ANC Utilization}

Finally, figure 1 reports the various reasons that the respondents provided to explain why they did not visit ANC services. These barriers included financial constraints, the bad attitude of the health care providers, lack of accessibility because ANC services were distant, influence of the husband, long waiting times, family matters, lack of awareness. A good number of them believed that ANC was not essential for their health (see Figure 1). 


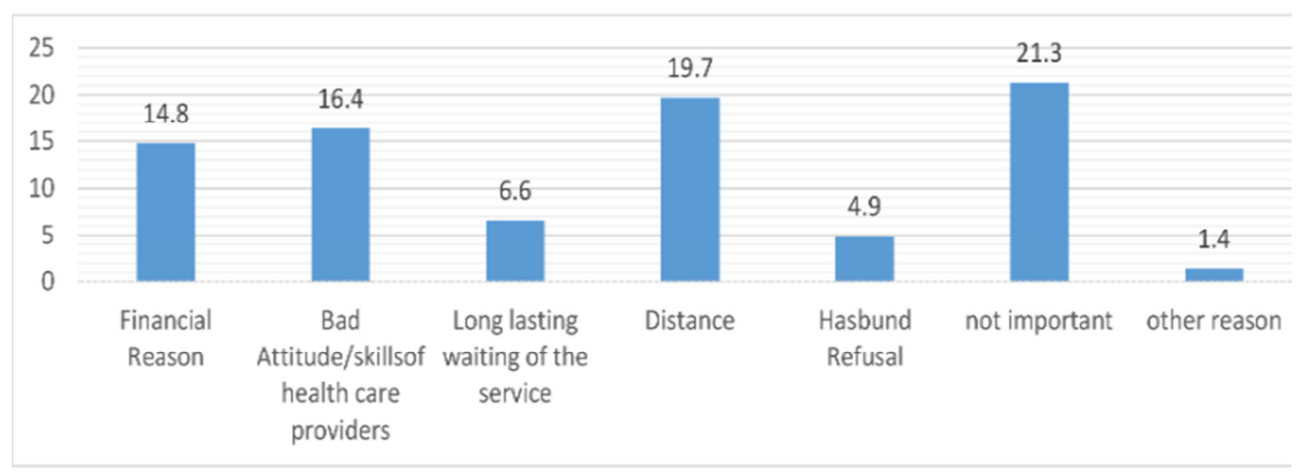

Figure 1. Barriers of ANC utilization.

\section{Discussion}

This study aims to assess ANC utilization rate, accessibility, and knowledge among mothers in Bosaso city of Somalia. This study revealed that $323(84.1 \%)$ of the mothers utilized ANC services during their last pregnancy, which is higher than previous study conducted in Guriel district of Somalia which stated $54 \%$ of the mothers utilized ANC services [24]. the high level of ANC attendance in Bosaso could be attributed to the availability of free primary healthcare services provided by the Ministry of Health of Puntland state of Somalia in collaboration with international organizations. Pregnant woman are recommended to attend at least four ANC visits at specific gestational ages during their pregnancy, therefor this study indicates that $28 \%$ completed the recommended number of ANC visits for pregnant women which is lower compared to a study conducted in HargeisaSomalia which reported that about $37.6 \%$ completed the required number of ANC visits [25]. Compared to East African countries, ANC coverage in Somalia was lower than other countries in the region, Somalia was $31 \%$, Kenya was $58 \%$, and Ethiopia was $74 \%$ [26-28]. This could be attributed to insecurity in the country, political setbacks, cultural issues and low level of education among Somali women.

In addition, most of the respondents $91 \%$ received ANC from primary health care centers. Among 323 women who attended ANC centers, $63.5 \%$ decided by their own to attend ANC. Possibly, this is due to awareness conducted by the Ministry of Health and other health organizations to pregnant women on the importance of ANC services, but nearly half of the respondents $48.6 \%$ started ANC visits during their second trimester, thus at relatively late stage of pregnancy. This is comparable to a study conducted in Menit-Shasha District of Ethiopia, where it was found that $71.1 \%$ of the mothers started ANC during their second trimester [29]. As shown in Table 3, $15.9 \%$ of the respondents had never attended ANC due distance of the health centers, financial constraints, poor knowledge of the respondents and husbands, poor attitude of the healthcare providers and time and family related issues.

Most of the middle aged women (27-37 years), about 51\%, used the ANC service better than other age groups. Again, this is similar to a study conducted in Nigeria, which showed that there is higher utilization of ANC services among middle age group than other age groups [30]. It is important to note that the majority of the mothers (88.5\%) using ANC services were married. About $88 \%$ of the study participants were housewives and most of them attended ANC service. Regarding the education level of mothers, nearly half of them $(40.9 \%)$ had primary level of education. The findings of this study differs from another study conducted in Ibadan - Nigeria which showed that majority of the mother $(55.8 \%)$ were of secondary level [31]. This can be attributed to lack of functional government which can provide formal education services to Somali children. In fact, in Somalia, most of the schools are private and most of the parents can't afford their children's education. In addition to that, poverty, long distances to school, security issues, social norms favoring boys' education than girls, and lack of female teachers, impede parents from enrolling children, particularly girls, in schools.

In regard to the respondents' knowledge on required $\mathrm{ANC}$ visits and beneficiaries of ANC services, this study revealed that the majority of the respondents $78.1 \%$ didn't know the minimum required ANC visits, but most of them $78.9 \%$ knew that both mother and fetus are ANC beneficiaries, in contrast to another study in Ethiopia which reported that $68.7 \%$ didn't know ANC beneficiaries. [29]

The majority of the mothers who attended ANC services $69.3 \%$ travelled on foot to get the service. Comparatively, another study conducted in Ethiopia stated that $93.5 \%$ travelled on foot to get the service [30]. Most of the mothers $43.7 \%$ travelled less than 30 minutes to reach health facilities for ANC services, whereas (45.2\%) of them took with health care provider 15 to 25 minutes.

\section{Conclusion and Recommendations}

In this study, we investigated the ANC utilization rate, accessibility, and knowledge among mothers in Bosaso city of Somalia. The study revealed that $84.1 \%$ of the respondents utilized ANC services during their last pregnancy, but only $28 \%$ of them completed the recommended number of ANC visits for pregnant women. The main barriers hindering the utilization of ANC services are due to distance of the health centers, financial constraints, poor knowledge and attitude of the respondents and their husbands, poor attitude of the healthcare providers and time and family related issues. 
Women who have some education visit the health centers, and those who live nearer to health facilities were found more likely to visit ANC services. Therefore, based on the study results, we recommend that the responsible bodies should focus on strengthening basic adult education and they should educate the women on income generating skills. It is also essential to uplift the awareness of the family/mothers about the availability of Antenatal care services in health facilities.

\section{Acknowledgements}

We would like to thank the data collectors, supervisors and the study participants for being involved in the study. Our gratitude goes to Bari regional health office of Ministry of Health-Puntland State of Somalia for their permission.

\section{References}

[1] World Health Organization. Human Rights and Health [Internet]. [cited 2019 Aug 17]. Available from: https://www.who.int/news-room/fact-sheets/detail/humanrights-and-health.

[2] World Health Organization. Millennium Development Goals (MDGs) [Internet]. WHO. [cited 2019 Aug 17]. Available from: https://www.who.int/topics/millennium_development_goals/abo ut/en/.

[3] World Health Organization, UNICEF, United Nations, Department of Economic and Social Affairs, Population Division, World Bank. Trends in maternal mortality: 1990 to 2015: estimates by WHO, UNICEF, UNFPA, World Bank Group and the United Nations Population Division [Internet]. 2015 [cited 2019 Aug 10]. Available from: http://www.who.int/reproductivehealth/publications/monitorin g/maternal-mortality-2015/en/.

[4] World Health Organization. Maternal mortality [Internet]. [cited 2019 Aug 17]. Available from: https://www.who.int/news-room/fact-sheets/detail/maternalmortality.

[5] United Nations: UNCTAD, editor. The least developed countries-Entrepreneurship for structural transformation: beyond business as usual [Internet]. New York Geneva: United Nations; 2018. 159 p. (The least developed countries report). Available from: https://unctad.org/en/PublicationsLibrary/ldcr2018_en.pdf.

[6] Leeson PT. Better off stateless: Somalia before and after government collapse. J Comp Econ. 2007 Dec; 35 (4): 689710 .

[7] UNICEF Somalia. Child and Maternal Health [Internet]. [cited 2019 Aug 18]. Available from: https://www.unicef.org/somalia/health.html.

[8] World Health Organization: EMRO. Reproductive Health in Somalia [Internet]. [cited 2019 Aug 18]. Available from: http://www.emro.who.int/som/programmes/reproductivehealth.html.

[9] Keasley J, Blickwedel J, Quenby S. Adverse effects of exposure to armed conflict on pregnancy: a systematic review. BMJ Glob Health. 2017; 2 (4): e000377.
[10] Boerma T, Tappis H, Saad-Haddad G, Das J, Melesse DY, DeJong $\mathrm{J}$, et al. Armed conflicts and national trends in reproductive, maternal, newborn and child health in subSaharan Africa: what can national health surveys tell us? BMJ Glob Health [Internet]. 2019 Jun 24 [cited 2019 Aug 18]; 4 (Suppl 4). Available from: https://www.ncbi.nlm.nih.gov/pmc/articles/PMC6590971/.

[11] Chukwuma A, Ekhator-Mobayode UE. Armed conflict and maternal health care utilization: Evidence from the Boko Haram Insurgency in Nigeria. SocSci Med 1982. 2019 Apr; 226: 104-12.

[12] Yaya S, Uthman OA, Bishwajit G, Ekholuenetale M. Maternal health care service utilization in post-war Liberia: analysis of nationally representative cross-sectional household surveys. BMC Public Health [Internet]. 2019 Jan 8 [cited 2019 Aug 18]; 19. Available from: https://www.ncbi.nlm.nih.gov/pmc/articles/PMC6323818/.

[13] de Jongh TE, Gurol-Urganci I, Allen E, Zhu NJ, Atun R. Integration of antenatal care services with health programmes in low- and middle-income countries: systematic review. J Glob Health. 2016 Jun; 6 (1): 010403.

[14] Gure F, Yusuf M, Foster AM. Exploring Somali Women's Reproductive Health Knowledge and Experiences: Results from Focus Group Discussions in Mogadishu. Reprod Health Matters. 2015 Jan 1; 23 (46): 136-44.

[15] Sorbye IK. A Situation Analysis of Reproductive Health in Somalia [Internet]. UNICEF; 2009 Apr [cited 2019 Aug 18]. Available from: https://www.unicef.org/somalia/SOM_resources_finalRHSana lysis.pdf.

[16] Abdillahi HA, Sahlén K-G, Kiruja J, Bile K. Factors affecting utilization of antenatal care services among women of childbearing age in Hargeisa, Somaliland [Internet]. Available from:

https://www.umu.se/globalassets/organisation/fakulteter/medf ak/institutionen-for-epidemiologi-och-globalhalsa/somalia/hamda-a.-abdillahi.pdf.

[17] Birmeta K, Dibaba Y, Woldeyohannes D. Determinants of maternal health care utilization in Holeta town, central Ethiopia. BMC Health Serv Res. 2013 Jul 3; 13: 256.

[18] De Silva J, Amarasena S, Jayaratne K, Perera B. Correlates of knowledge on birth defects and associated factors among antenatal mothers in Galle, Sri Lanka: a cross-sectional analytical study. BMC Pregnancy Childbirth. 2019 Jan 17; 19 (1): 35 .

[19] Kyei-Nimakoh M, Carolan-Olah M, McCann TV. Access barriers to obstetric care at health facilities in sub-Saharan Africa-a systematic review. Syst Rev. 2017 06; 6 (1): 110.

[20] Yasuoka J, Nanishi K, Kikuchi K, Suzuki S, Ly P, Thavrin B, et al. Barriers for pregnant women living in rural, agricultural villages to accessing antenatal care in Cambodia: A community-based cross-sectional study combined with a geographic information system. PloS One. 2018; 13 (3): e0194103.

[21] Sumankuuro J, Crockett J, Wang S. Perceived barriers to maternal and newborn health services delivery: a qualitative study of health workers and community members in low and middle-income settings. BMJ Open. 2018 Nov; 8 (11): e021223. 
[22] Sumankuuro J, Mahama MY, Crockett J, Wang S, Young J. Narratives on Why Pregnant Women Delay Seeking Maternal Health Care During Delivery and Obstetric Complications in Rural Ghana. BMC Pregnancy Childbirth. 2019 Dec; 19 (1): 260 .

[23] Dalmar AA, Hussein AS, Walhad SA, Ibrahim AO, Abdi AA, Ali MK, et al. Rebuilding research capacity in fragile states: the case of a Somali-Swedish global health initiative. Glob Health Action. 2017; 10 (1): 1348693.

[24] Fardowsa Omar, Dr. Felix Musili and Dr. Onditi Kodhiambo M; Socio-demographic and economic factors associated with anc attendance among women of reproductive age; Journal of Health, Medicine and Nursing; Vol. 5, Issue 1. No. 4, pp 48$59,2020)$.

[25] (Hamda A. Abdillahi, Klas-Göran Sahlén, Jonah Kiruja, Khalif Bile; Factors affecting utilizationof antenatal care (anc) services among women of childbearing age in, hargeisa, Somaliland; ume university - Sweden; https://www.umu.se/globalassets/organisation/fakulteter/medf ak/institutionen-for-epidemiologi-och-globalhalsa/somalia/hamda-a.-abdillahi.pdf).
[26] Directorate of National Statistics, Federal Government of Somalia. The Somali Health and Demographic Survey 2020.

[27] Kenya National Bureau of Statistics; Kenya Demographic and Health Survey 2014.

[28] Ethiopian Public Health Institute (EPHI) [Ethiopia] and ICF. 2019. Ethiopia Mini Demographic and Health Survey 2019: Key Indicators. Rockville, Maryland, USA: EPHI and ICF.

[29] Teka Senay Wolderufael; Factors Influencing Antenatal Care Service Utilization Among Pregnant Women in Pastoralist Community in Menit-Shasha District, Ethiopia; International Journal of Medical Research \& Health Sciences, 2018, 7 (5): 143-156.

[30] Dubale Dulla, Deresse Daka, Negash Wakgari; Antenatal Care Utilization and Its Associated Factors among Pregnant Women in Boricha District, Southern Ethiopia; Diversity and Equality in Health and Care (2017) 14 (2): 76-84.

[31] M. D Dairo, K. E. Owoyokun, FACTORS AFFECTING THE UTILIZATION OF ANTENATAL CARE SERVICES IN IBADAN, NIGERIA, Benin journal of postgraduate medicine, Vol. 12 No. 1 December, 2010. 